\title{
CONSUMO DA EXPERIÊNCIA E TURISMO CONTEMPORÂNEO: a Campanha Can't Skip Portugal
}

\author{
Patrícia de Souza Figueiredo Lima
}

\begin{abstract}
RESUMO
Com o objetivo de perceber as transformações nas práticas e discursos de consumo turístico contemporâneos, buscamos discutir neste artigo de que modo a publicidade realizada pelo Turismo de Portugal representa o país enquanto destino turístico em um filme publicitário da campanha online, lançada em 2017, voltada para os públicos internacionais, intitulada Can't Skip Portugal. Buscamos perceber as estratégias contruídas e a alusão feita às emoções e à experiência enquanto objetos a serem consumidos pelos visitantes, a partir da articulação com considerações teóricas oriundas da Sociologia do Turismo e da Cultura a respeito da atividade turística e do "consumo da experiência" e da perspectiva dos Estudos Culturais.
\end{abstract}

\section{CONSUMPTION OF EXPERIENCE AND CONTEMPORARY tourism: The CAMpaign Can't Skip Portugal}

\begin{abstract}
In order to understand the transformations in contemporary tourist consumption practices and discourses, we have tried to discuss in this article how the publicity carried out by Turismo de Portugal represents the country as a tourist destination in an online campaign, launched in 2017, aimed at the international public, entitled Can't Skip Portugal. We seek to understand the built strategies and the allusion made to emotions and experience as objects to be consumed by visitors, articulating theoretical considerations from the Sociology of Tourism and of Culture regarding tourism activity and "consumption of experience" with the perspective of Cultural Studies.
\end{abstract}

\section{KEYWORDS}

Cultural Studies; consumption of experience; Portugal; publicity; tourism 


\section{INTRODUÇÃo}

Com o objetivo de perceber como o turismo e o consumo da experiência estão relacionados de forma cada vez mais intensa na contemporaneidade, buscamos discutir neste artigo de que modo a publicidade realizada pelo Turismo de Portugal constrói suas promessas enunciativas na recente campanha voltada aos públicos internacionais intitulada Can't Skip Portugal. Quisemos perceber as estratégias contruídas e a alusão feita às emoções de cada um dos possíveis visitantes a serem vivenciadas em um único destino: Portugal.

Diferente de uma corriqueira experiência de consumo, no consumo da experiência a experiência é o próprio objeto, material ou imaterial a ser consumido (Pereira, Siciliano \& Rocha, 2015) mobilizando uma verdadeira "economia da experiência" que inclui atividades de lazer, jogos, turismo e distração voltados para gerar emoção, laços, afetos e sensações (Lipovetsky, 2006, p. 54).

Nesta abordagem, inicialmente, serão contextualizados o consumo e o turismo como fenômenos da cultura de massa contemporânea marcada pela globalização e mobilidade, à luz das abordagens de alguns dos teóricos da Sociologia da Cultura e do Turismo (Bauman, 1998, 2007; Krippendorf, 2009; Lipovetsky, 2007, 2008; Martins, 2017; Urry, 2001). Em seguida, será realizada uma breve leitura interpretativa de um filme publicitário da referida campanha, à luz dos Estudos Culturais, relacionando-o com o enquadramento teórico aqui apresentado.

\section{TURISMO E CONSUMO DA EXPERIÊNCIA}

Os turistas (...) partem porque acham o lar maçante ou não suficientemente atrativo, demasiadamente familiar e contendo demasiadamente poucas surpresas, ou porque esperam encontrar em outro lugar uma aventura mais excitante e sensações mais intensas do que a rotina doméstica jamais é capaz de transmitir. (Bauman, 1998, p. 116)

De acordo com dados da Organização Mundial do Turismo - OMT, em 2017, foi registrado um aumento de $7 \%$ no número de deslocamentos internacionais em relação ao ano anterior, sendo contabilizados 1,3 bilhão de viagens internacionais ${ }^{1}$, o que gerou \$1,237 bilhão de receitas, representando 10\% do Produto Interno Bruto mundial. Os números demonstram que o turismo adquire importância cada vez maior entre consumidores espalhados por todo o planeta. A atividade turística entra no rol de produtos e serviços necessários aos indivíduos contemporâneos, impulsionando-os a viajarem em um ritmo cada vez mais crescente.

A atividade turística mobiliza diferentes anseios, atores e dinâmicas sociais entre as comunidades emissoras e receptoras. Promove intercâmbios econômicos e simbólicos e define-se a partir dos imaginários coletivos a respeito dos lugares, ao mesmo tempo que preenche, ou tenta preencher, lacunas que surgem em rotinas pouco atrativas, sobretudo no ritmo frenético dos grandes centros urbanos.

\footnotetext{
' Informações disponíveis no site da OMT: http://media.unwto.org/content/infographics
} 
Krippendorf (2009) aponta que os indivíduos aproveitam todas as oportunidades para viajar e fugir do cotidiano com a maior frequência possível porque não se sentem mais à vontade onde se encontram, trabalham ou moram. Viajam para se desfazerem, ainda que temporariamente, de suas rotinas massificantes. Por meio do consumo simbólico de paisagens, culturas e experiências diferentes, os sujeitos se tornam aptos a "suportar" o cotidiano durante certo tempo. Do mesmo modo, Bauman (1998) afirma que os turistas escolhem (ou pensam que estão escolhendo) viajar porque acham seus lares maçantes, pouco atrativos, demasiadamente familiares e contendo demasiadamente poucas surpresas.

Assim, a massificação da experiência turística é reflexo da massificação da vida contemporânea, pois o turismo tende a ser fluído e efêmero assim como são as relações de consumo na contemporaneidade.

Caracterizados enquanto "mestres supremos da arte de misturar sólidos e líquidos", Bauman (1998, p. 114), afirma que os turistas realizam a façanha de não pertencer ao lugar visitado. Viajando sem a necessidade de aculturar-se, os turistas podem sair para o próximo destino assim que tal experiência ameace sair do controle ou quando aventuras ainda mais interessantes aparecem pelo caminho: "o nome do jogo é mobilidade: a pessoa deve poder mudar quando as necessidades impelem, ou os sonhos o solicitam (...) a peculiaridade da vida turística é estar em movimento, não chegar" (Bauman, 1998, p. 114).

A crise da experiência contemporânea é considerada por Martins (2017, p. 19) como a de um "quotidiano acentrado, sem fundamento, que vive das emoções, e não de ideias, num tempo de velocidade, acelerado, de mobilização total ou infinita". Segundo o autor, as tecnologias sintetizadas no ecrã possibilitam mobilizar-se em permanência. Acrescentamos que, seduzidos pelas imagens digitais, os indivíduos viajam, em matéria, em busca de novas emoções e experiências, impulsionando, assim, o turismo em todo o mundo.

A escolha de um destino é motivada por múltiplos fatores. O mercado dos destinos turísticos globais faz crescer a construção de campanhas de marketing voltadas para diferentes públicos e mercados. Acompanhando as necessidades e as vontades dos homens e mulheres contemporâneos ávidos por novas experiências, órgãos de planejamento turístico, após análises detalhadas de todos os nichos e segmentos de turismo possíveis, escolhem o posicionamento de mercado mais competitivo. Busca-se, ao mesmo tempo, diversificar e individualizar as experiências, ou seja, oferecer uma gama cada vez maior de produtos de modo a atender demandas e anseios personalizados.

Entretanto, a entidade turística de um objeto, seja ele patrimônio "natural" ou "cultural", conforme assinala Santos (2008), é constituída por um conjunto de convenções que regulam a ação comunicativa estética. Situando o turismo entre as práticas de consumo na modernidade tardia que expressam o "signo do excesso", a "cultura da urgência", "hiperfuncionalidade" e o movimento e declínio das tradicionais formas de sentido, Santos (2008, p. 112) defende que a atividade turística reflete os "grandes sistemas de representação de mundo [que] são tomados como objectos de consumo efémeros e em permanente reciclagem". 
A prática turística está inserida, portanto, nos modos de vida e de consumo contemporâneos e, como tal, incorpora e reifica os aspectos que marcam as dinâmicas sociais, econômicas e simbólicas que integram as lógicas de consumo e consumismo que se estabelecem na atualidade, a exemplo da liquidez, efemeridade, individualização e descartabilidade. Bauman (2007) considera o consumo como "principal força propulsora e operativa da sociedade", influenciando, dentre outras dimensões, os processos de identificação individual e coletivos. Para o teórico, no ambiente líquido-moderno, a noção de tempo é renegociada, sendo este marcado pela descontinuidade, inconsistência e falta de coesão e por uma "multiplicidade de instantes eternos - eventos, incidentes, aventuras, episódios" (Bauman, 2008, p. 46). Assim, consideramos que o modo de consumir e a própria relação com o tempo que marca o consumo de atividades ligadas ao lazer e ao turismo também contribuem para os processos de inter-relação e autoidentificação dos sujeitos e dos grupos com os quais se relacionam.

Ainda que ressalte o caráter do olhar como algo fundamental ao turismo, Urry (2001, p. 29) também faz referência à importância do turismo enquanto atividade de consumo, pois "o devaneio e a expectativa, ambos disfarçados, são processos fundamentais para o consumo moderno". O autor reflete que os indivíduos não procuram a satisfação a partir da aquisição e uso dos produtos, mas sim a partir da expectativa, da procura do prazer, que se situa na imaginação. Deste modo, a motivação básica das pessoas, em relação ao consumo, não é, portanto, simplesmente materialista:

elas procuram, sim, vivenciar "na realidade" os dramas agradáveis que já vivenciaram em sua imaginação. No entanto, como a "realidade" jamais poderá propiciar os prazeres aperfeiçoados com que o indivíduo se depara nos devaneios, cada compra conduz à desilusão e ao anseio por produtos sempre mais novos. Existe uma dialética da novidade e da insaciabilidade no âmago do consumismo contemporâneo. (Urry, 2001, p. 30)

Contudo, o autor argumenta que o devaneio e a expectativa de novas e diferentes experiências que marcam o turismo não são autônomos, pois "envolvem o trabalho com a propaganda e outros conjuntos de signos, gerados pela mídia, muitos dos quais dizem respeito a processos de emulação social" (Urry, 2001, p. 30).

A comercialização das experiências envolve o redimensionamento de inúmeros produtos e serviços, para além da atividade turística, de modo a oferecer uma diversidade de vivências e experiências ao novo consumidor. Assim, o discurso midiático, incluindo a publicidade, se retroalimenta, ao mesmo tempo que reforça, essas e outras transformações nas práticas de consumo contemporâneas.

Lipovetsky (2007, p. 54) trata da "economia da experiência" para se referir às atividades de lazer, jogos, turismo e distração que oferecem um conjunto de "vivências, acontecimentos inesperados e extraordinários capazes de gerar emoção, laços, afetos, sensações" ao que chama de hiperconsumidor. Deste modo, o turismo organiza os cenários de modo a oferecer, em forma de pacotes turísticos cada vez mais personalizados, o consumo da experiência, seja em centros históricos ou aldeias bem preservadas, seja em parques de diversões. 
Assim, construindo uma gama de sensações e vivências,

as cidades históricas tornam-se cidades temáticas pensadas para responder à procura de "autenticidade" que ali leva turistas ansiosos por fugir à rotina, ávidos de ambientes e exotismos folclóricos. Em alguns parques temáticos são reconstruídas virtual ou imaterialmente cidades antigas, reservas de índios, animais em vias de extinção, momentos de nossa história. Outros recriam climas específicos indoors, florestas tropicais, tempestades de neve, paisagens marítimas; outros ainda simulam erupções vulcânicas ou sismos. (Lipovetsky, 2007, p. 54)

Com o objetivo de definir operacionalmente o conceito, Pereira, Siciliano e Rocha (2015, p. 9) consideram o "consumo de experiência" como o "o uso social, reforçado pelo sistema de classificação e de significação da sociedade, de bens (consumo), que sejam, em si mesmos, as práticas e as interações sociais nele envolvidas (experiência)". Neste sentido, a experiência é em si o próprio objeto a ser consumido. Diferentemente de uma corriqueira experiência de consumo, para estes autores, o consumo de experiência "pressupõe a total imersão do indivíduo em um ambiente alusivo a uma memória anterior e ao deslocamento do significado de identidades, objetos, ambientes, entre outros elementos constitutivos do mundo real" (Pereira, Siciliano \& Rocha, 2015, p. 6).

Diante disso, os autores propõem um conjunto de pressupostos que devem ocorrer simultaneamente para que uma prática de consumo possa ser considerada "consumo de experiência":

(1) um espaço físico ou virtual, cujo acesso pressupõe, necessariamente, alguma espécie de "preço", e que seja intencionalmente preparado para que ele vivencie sensações, emoções e impressões dentro de um tempo delimitado e pontual; (2) uma preparação ritualizada anterior; (3) uma narrativa, fragmentos dela ou alguma referência previamente conhecida; (4) a participação consensual do indivíduo ou do grupo, uma espécie de acordo tácito entre os participantes com relação à suspensão da descrença e aos aspectos lúdicos, mágicos ou imaginados que serão, naquele espaço, apresentados como "simulacro"; (5) o deslocamento de significados subjetivamente experimentado; e, finalmente, (6) que tal repertório dotado de significado tenha total correspondência com a narrativa de origem. (Pereira, Siciliano \& Rocha, 2014, p. 6)

Deste modo, compreendemos que os discursos e as práticas turísticas, com o objetivo de oferecer ao consumidor-turista aquilo que este deseja encontrar nos destinos turísticos, sejam experiências inesquecíveis ou culturas únicas e/ou exóticas, moldam e simplificam a complexidade dos lugares em objetos de consumo. A esse respeito, Santos $(2008$, p. 116) considera que a cultura construída situacionalmente face às visitas, transfigurada "pela índole do turismo", se faz valer pelo espetáculo, pelas emoções que desperta, pelas evocações que transporta e não por um significado que possa ser portadora. 
A própria relação com a arte também é reconfigurada a partir da lógica de "turistificação" dos equipamentos culturais, especialmente em destinos que recebem um grande número de turistas ${ }^{2}$. A esse respeito, Lipovestky e Serroy (2008, p. 131) observam que vivemos um "tempo de patrimonialização generalizada e de inflação museológica: os lugares importantes da história são visitados por milhões de turistas e as exposições prestigiosas de pintura atraem centenas de milhares de visitantes"; assim, segundo os autores, as pessoas passam horas em filas para entrar em museus, mas não leem os poetas, os clássicos: “já não se vê Homero nem Petrarca, mas visita-se a Acrópole e os palácios de Florença. São raros os leitores de A nova Heloísa, mas esgotam as salas de ópera" (Lipovetsky \& Serroy, 2008, p. 131).

Os autores consideram que a cultura artística nunca teve uma audiência tão massiva. Contudo, essas audiências de turistas estariam marcadas pela lógica consumista, na qual, através de um zapping apressado, as obras de arte são consumidas como fast food, sem nenhuma veneração, recolhimento ou silêncio, mas com a descontração característica de quem está de férias. Assim, para Lipovestky e Serroy (2008), a aura da obra de arte é substituída por outro tipo de experiência: a experiência turística. Aqui, as obras passam a funcionar como objetos de animação das massas e não de contemplação estética e elevação espiritual, mas divertimento, emoções secundárias e ocupação do tempo livre. O reconhecimento pelas grandes obras não foi perdido, mas a admiração passou a ser imediata, sem formação ou trabalho intelectual.

Ao mesmo tempo, o processo massivo de "turistificação" dos lugares tem afetado o cotidiano das pessoas que habitam nos sítios que recebem grandes fluxos turísticos em suas mais diversas dimensões, que vão desde a dificuldade de circulação e utilização confortável dos meios de transporte disponíveis, passando pelo inflacionamento de produtos de consumo, a poluição sonora, visual ou excessiva produção de resíduos, ou ainda encontros interculturais por vezes pouco amistosos, dentre muitos outros.

Outro traço que marca o papel da mobilidade e do consumo das experiências na contemporaneidade é a sua influência nas (re)configurações identitárias. O consumo e - lazer passam a ser considerados enquanto investimentos identitários. Ainda que Ribeiro (2010, p. 193) considere que "a viagem, a transição, a estranheza, o intermitente" sejam raramente associados ao conceito de identidade nos intensos debates teóricos, a viagem, segundo esta autora, talvez seja o traço mais marcante da modernidade, visto que é "mudança, abertura, risco, irradiação, fusão".

Seja como mecanismo de fuga de rotinas maçantes, seja para viver novas emoções e experiências, numa lógica de mobilidade e efemeridade, seja para servir como mecanismo de diferenciação e identificação dos indivíduos, ou tudo isso ao mesmo tempo, o turismo é inegavelmente uma marca das sociedades contemporâneas.

Em face deste contexto, será apresentado, na próxima seção, como o Turismo de Portugal, órgão responsável pelo planejamento, gestão e promoção do turismo em Portugal, elaborou sua recente campanha online de promoção internacional de turismo: Can't Skip Portugal. O objetivo é observar, através de uma leitura interpretativa dos discursos e

${ }^{2}$ O Museu do Louvre, em Paris, recebeu, somente no ano de 2016, 7,4 milhões de visitantes. Informações disponíveis em https://www.louvre.fr/en 
imagens presentes em um filme publicitário desta campanha, como as representações e as promessas discursivas são voltadas para as transformações no consumo contemporâneo, especialmente o que denominamos aqui de "consumo da experiência".

\section{Análise empírica: Can't SkIP Portugal}

\section{Sistemas de RepresentaÇÃo a A PerspeCtiva dos Estudos Culturais}

A partir da compreensão que a cultura está presente em todas as práticas sociais (Hall, 2003), incluindo os modos de vida e o consumo contemporâneos, nosso interesse de análise é perceber os modos de representação através do discurso publicitário, circunscritos às dinâmicas da atividade turística, e como este reitera e reforça determinados imaginários e práticas de consumo acerca dos destinos turísticos, especialmente ao que se denomina aqui enquanto "consumo de experiência".

Lisboa, Filho e Moraes (2014) defendem a legitimidade dos Estudos Culturais enquanto aporte teórico-metodológico capaz de orientar pesquisas em comunicação, incluindo as mídias audiovisuais, considerando a natureza cultural das produções audiovisuais e seus processos de produção, circulação e consumo. Do mesmo modo, Escosteguy (2007, p. 4) também reivindica que, mesmo que uma abordagem integrada da produção e do consumo possa não ser exclusiva dos Estudos Culturais, essa tradição gerou debates e esforços neste sentido após o "desenvolvimento de uma vertente mais contextualista dos Estudos de Recepção, que diminuiu o interesse em relação ao conteúdo propriamente dito dos textos midiáticos, concentrando sua atenção mais no cotidiano de um grupo em que se observa, entre tantas outras atividades, o uso dos meios".

Considerando que a cultura está relacionada com "significados compartilhados", Hall (2003) defende que a linguagem é o meio privilegiado através do qual nós "produzimos sentido" das coisas, através do qual o significado é produzido e trocado, já que estes podem somente ser compartilhados através de nosso comum acesso à linguagem. Dessa forma, a linguagem é central para o significado e cultura e é um repositório-chave de valores culturais e significados, pois funciona como um sistema de representação.

Para Hall (2003), especialmente nos Estudos Culturais e na Sociologia da Cultura, há uma tendência em enfatizar a importância do significado para a definição de cultura. Cultura não apenas como um conjunto de coisas - romances e pinturas ou programas de TV e comédias - mas como um processo, um conjunto de práticas. A cultura, nesta perpectiva, organiza e regula práticas sociais, influencia nossa conduta e consequentemente possui efeitos práticos e reais.

Assim, o "circuito da cultura" proposto por Gay, Hall et al. (citado por Hall, 2003, p. 1) sugere que os significados são produzidos em muitos lugares diferentes e circulam através de variados processos ou práticas, incluindo a construção de identidades e demarcação da diferença, na produção e consumo, assim também como na regulação da conduta social.

Retomando a questão da representação, Hall (2003) defende que sons, palavras, notas musicais, gestos, expressões, roupas, dentre outras formas de representação são 
veículos ou meios que carregam significados porque operam como símbolos que representam significados que nós desejamos comunicar, ou seja, funcionam como signos.

Deste modo, faremos uma leitura interpretativa, a partir de uma descrição atenta, de modo a perceber o modo como o filme publicitário divulgado pelo Turismo de Portugal representa o país enquanto destino turístico, procurando os significados que the subjazem, e sua articulação com o consumo turístico contemporâneo. No âmbito deste trabalho, portanto, não iremos abarcar o circuito da cultura proposto pelo autor. As instâncias de produção e modos de recepção desta e outras peças publicitárias da Turismo de Portugal estão sendo estudadas em outros trabalhos ${ }^{3}$.

\section{Filme pUblicitário: CAN'T Skip FreEdom}

Considerado como prioridade estratégica pelo governo português ${ }^{4}$, atualmente, o turismo é a maior atividade exportadora de Portugal, de acordo com o documento Estratégia Turismo 2027- ET27. Este documento sintetiza as estratégias para o turismo no país de 2017 a 2027, combinando uma visão a longo prazo com ações a curto e médio prazos e define, dentre outras metas, aumentar, em todo o território, o número de dormidas, na ordem de 80 milhões por ano, e crescer para 26 mil milhões de euros em receitas geradas.

Integrado ao Ministério da Economia e da Inovação, o Turismo de Portugal é a Autoridade Turística Nacional, responsável pela promoção, valorização e sustentabilidade da atividade turística em Portugal e reúne todas as competências institucionais relativas à dinamização do turismo em Portugal, incluindo a oferta e a demanda turísticas 5 . Dentre suas funções, está a promoção do destino Portugal nacional e internacionalmente, incluindo ações de comunicação e relacionamento junto aos mercados, dentre as quais a gestão do site da VisitPortugal ${ }^{6}$ e outras mídias socias (canal do YouTube, páginas no Facebook, Instagram, Twitter, Google+, dentre outros). No ano de 2017, Portugal recebeu o prêmio de "Melhor Destino do Mundo", do World Travel Awards7, o que vem confirmar como o país tem realizado uma estratégia de marketing "agressiva" frente os mercados internacionais.

Com o slogan Can't Skip Portugal, a campanha de promoção internacional de turismo de Portugal para 2017 e 2018 foi lançada pelo Turismo de Portugal (TP), exclusivamente em meio digital para divulgação do país em 20 países $^{8}$, definidos como mercados alvo. Segundo informações disponíveis no site do TP, a campanha "aposta na

\footnotetext{
${ }^{3}$ No âmbito do nosso projeto de investigação no Programa Doutoral em Estudos Culturais, na Universidade do Minho.

${ }_{4}^{4}$ Disponível em http://estrategia.turismodeportugal.pt/o-que-e

5 Informações disponíveis no site do Turismo de Portugal, em www.turismodeportugal.pt

6 Disponível em www.visitportugal.com

7 “World Travel Awards" turismo e hotelaria. Informações disponíveis no site https://www.worldtravelawards.com/about\#googtrans/en/en

${ }^{8}$ Reino Unido, Alemanha, França, Espanha, Brasil, EUA, China, Holanda, Itália, Irlanda, Rússia, Canadá, Índia, Noruega, Suécia, Dinamarca, Finlândia, Áustria, Bélgica e Polónia, segundo a Turismo de Portugal. Ver http://www.turismodeportugal.pt/Português/turismodeportugal/destaque/Pages/TurismodePortugalcomCampanhalnternacionalem2opaises.aspx
} 
mensagem de que já não há como passar ao lado de um destino como este: autêntico e único, com tanto para ver, provar, sentir e experimentar" (grifo nosso). A intenção da campanha, portanto, é remeter aos sentidos e às experiências e prometer ao consumidor a realização de uma experiência "autêntica".

No lançamento da campanha, em março de 2017 , foram lançados quatro filmes publicitários, elaborados pela agência Partners, nos quais três personagens estrangeiros (um inglês, uma francesa e um alemão) narram reflexões a respeito de suas inspirações e anseios, enquanto vivem diferentes experiências em belos sítios, de várias regiões de Portugal. Os filmes estão disponíveis, em inglês, no canal do YouTube Visit Portugal9, com a opção de legendas em outros idiomas (francês, espanhol, alemão, italiano, russo e português). A seguinte descrição é feita nesta seção de vídeos do canal: “a vida passa por nós, o tempo passa por nossos dedos. Decida sua próxima parada, escolha o seu próximo destino. Não pode pular (ou ignorar) a vida. Não pode nos pular/ignorar. Não pode pular/ignorar Portugal".

Ao início dos três vídeos é exibido um rápido texto, com letras brancas em um fundo preto, na qual é informado que o filme foi gravado inteiramente no mês de dezembro, durante o inverno. Em seguida, surgem imagens de cada um dos personagens e o áudio de suas reflexões.

No filme Can't Skip Inspirations, uma jovem, com pronúncia francesa, percorre diferentes lugares, concentrados em paisagens urbanas, com edificações históricas bem preservadas e, ao mesmo tempo, construções modernas com arquiteturas arrojadas, enquanto reflete sobre aquilo que lhe inspira. Na descrição do vídeo, somos informados que "Chloe é uma jovem que está cansada de sentir-se sem inspiração com a vida. Ela quer alegria, quer entusiasmo, quer beleza. Ela sai para um lugar onde ela se encontra seduzida pela história, por velhas tradições vestidas de novo, por uma nova vida" Embora circule por centros urbanos, as cidades e lugares por onde a jovem percorrem parecem estar vazios, para que ela possa buscar beleza e inspiração através de ambientes tranquilos e organizados.

No filme intitulado Can't Skip New Beginnnings, um homem, aparentando ter mais de 60 anos, com acento alemão, fala sobre os novos começos possibilitados pela vida enquanto vive o que parece ser, para ele, novas experiências: observa e sente o vento em seu rosto entre belos vales de montanhas, realiza pesca e come alegremente entre amigos em um barco, caminha por entre aldeias históricas, é reconhecido por pessoas que acenam para ele enquanto toma um vinho em um restaurante local e até mesmo surfa (ou pretende surfar, não se sabe efetivamente se ele surfou) em pequenas ou grandes ondas. Ao mesmo tempo em que experimenta essas novas vivências, o personagem narra um discurso que reflete e exalta o envelhecimento não como um fim ("Não é uma questão de finais felizes, mas de novos começos. Ainda não é o momento para parar"), mas apenas como uma etapa da vida e não um momento de parar, mas de recomeçar,

\footnotetext{
9 Disponível em https://www.youtube.com/user/VisitPortugal

10 Todas as transcrições dos diálogos dos vídeos aqui descritos a partir deste ponto foram realizadas a partir da tradução, em português, disponibilizada e adaptada a partir das legendas disponíveis no canal Visit Portugal do YouTube.
} 
em um novo lugar "de afetos, onde a comida tem sempre o sabor a dias felizes, onde o calor humano e os dias de verão nos abraçam e o mar nos espera sereno". A mensagem deste filme parece querer atrair não apenas turistas, mas também pessoas para viver de forma permanente em Portugal.

Já no filme, com duração de 3'04", intitulado Can't Skip Freedom - no qual concentraremos nossa observação, o personagem, jovem, com sotaque inglês, surge inicialmente caminhando por um cenário aparentemente deserto, entre montanhas verdes, fazendo reflexões sobre sua existência. A escolha por uma descrição mais detalhada e atenta deste vídeo se deu porque a promessa discursiva do "consumo da experiência" parece estar mais evidente nesta narrativa.

Inicialmente, o personagem revela um sentimento de "desencaixe" com o contexto em que vive ("Quantas vezes saíste antes da hora, cancelaste uma reunião ou mudaste os teus planos? Quantas vezes disseste "eu vou" e ficaste no mesmo lugar, com os pés agarrados ao chão? Quantas vezes olhaste para a tua vida de um outro ponto de vista e percebeste, que afinal naquele momento, estavas no lugar errado?") - neste momento o cenário é alternado com imagens do mesmo personagem, com terno e gravata, caminhando apressado em um grande centro urbano, por entre "arranha céus", em um ambiente cinza, quando para e suspira com uma expressão de cansaço. Em seguida, o mesmo personagem mergulha, em um oceano azul (não apenas representando o mar, mas aludindo a grandes oportunidades e experiências) e, voltando-se para quem está do outro lado do ecrã, diz:

escuta, nós somos do tamanho daquilo que vemos e não do tamanho das coisas que temos. Um homem precisa ver com os próprios olhos, caminhar o mundo com os próprios pés, ter o sol a lhe queimar as costas e a estrada a lhe queimar os pés. O que é mais severo: o vento gelado do topo da montanha ou o calor escaldante de uma planície? Só há uma forma de descobrir: ver tudo isto com os nossos próprios olhos e não pelos nossos telemóveis inteligentes que mostram paisagens partilhadas um milhão de vezes.

Ao mesmo tempo que vai fazendo suas reflexões, o personagem circula por belas paisagens naturais, tais como campos, praias, alto de montanhas, florestas, rochedos, riachos, todos, até então, sem nenhuma presença humana além dele. Então, surge brevemente a imagem de uma bela mulher, jovem, de biquíni azul, que permanece silenciosa, enquanto caminha em uma praia sem mais ninguém.

Depois, o personagem continua: "por isso anda, vem ver... Mas olha com olhos de quem vê e quer ver, guarda-as aqui [enquanto aponta para cabeça] e aqui [apontando para o coração]. Larga o telemóvel e vai!". Então o personagem segue caminhando, como quem vai descobrindo novas e inesperadas paisagens, enquanto reflete:

viajar faz-nos florescer e acordar (...) Em 20, 30 ou 40 anos vamos arrepender-nos do que não fizemos. Por isso, navega para longe do porto, deixa que o vento sopre nas tuas velas e explora, sonha e descobre. Acredita que o céu te vai parecer muito mais azul. 
Neste ponto, a mulher de biquíni azul reaparece, mergulhando e emergindo entre águas também azuis.

Sua reflexão continua: “já deves ter lido: Quando algo de bom acontece, faz uma viagem para comemorar. Quando algo de mau acontece faz uma viagem para esquecer. E quando nada acontece, viaja para que algo aconteça". A mulher então retorna, mas agora ao lado do personagem principal, justamente no momento em que ele fala que devemos viajar para que algo aconteça. Ao final, ele termina dizendo: "lembra-te sempre disto... é a pura verdade e esta é a prova, está nas nossas mãos todos os dias, só temos de saber ler os sinais. Porque no final de contas... não podemos deixar de viver". Então aparecem as mensagens, em sequência: “Can't skip love. Can't skip joy. Can't skip freedom. Can't skip us. Can't Skip Portugal”. E, finalmente, a marca Visit Portugal. Somente então foi identificado o lugar onde estão todas as diferentes paisagens exibidas ao longo do filme. O espectador, aliás, só fica sabendo que se trata de um vídeo promocional de um destino turístico quando o vídeo é encerrado.

O discurso é o de um carpe diem pós-moderno: aproveite o dia, saia da frente do ecrã, viva, descubra e sinta com seus próprios olhos as incríveis experiências que uma viagem pode proporcionar. Desligue-se de uma vida enfadonha ou que te aprisiona e vá descobrir e sonhar em diferentes lugares. Assim como Bauman (2008) afirma que as pessoas viajam para fugirem de rotinas demasiadamente pouco atrativas, o personagem central deste vídeo faz o convite para que o espectador viaje "para que algo aconteça". O lugar poderia ser qualquer outro do mundo. Não é exibido nem um ícone turístico facilmente alusivo ao país - nenhum símbolo cultural, patrimônio reconhecido internacionalmente, comida, bebida, vestuário - nenhum objeto que represente simbolicamente ou faça referência direta a Portugal. A estratégia que parece ter sido adotada foi a de seduzir por meio de belas imagens e de um discurso envolvente, e somente ao final surpreender o espectador com a informação de que todas aquelas experiências podem ser vividas em um só lugar: Portugal. E, considerando que esta campanha está voltada majoritariamente para o público europeu, o objetivo parece ser também enfatizar que todas essas experiências podem ser vividas logo ao lado, em um país vizinho, em qualquer época do ano, inclusive no inverno.

É oferecido ao espectador uma amostra (ironicamente através de um ecrã) em pouco mais de três minutos, de experiências e emoções a serem descobertas em uma única viagem: pode ser mergulhar no mar azul, caminhar por entre cenários naturais bem preservados ou encontrar com uma mulher misteriosa em um ambiente quase que intocado. Utilizando uma lógica de "tipificação positiva" (Gastaldo, 2013) da realidade representada pela publicidade turística, não há filas, pessoas aglomeradas, congestionamentos, vendedores ambulantes, nada que remeta à antiga vida cinza dos grandes centros urbanos ou turísticos. As imagens sugerem que tudo aquilo está à espera para ser "descoberto". Compreendendo que a publicidade turística opera sob a lógica de antecipação da experiência a ser vivida, Conceição (1998, p. 72) considera que esta retrata aquilo que o turista pretende encontrar, transformando a viagem em algo que reflita "o universo, os gostos e as aspirações de quem deseja partir". A partir dessa compreensão, podemos perceber que a campanha Can't Skip Portugal, pretende oferecer uma 
antevisão de modo a preencher as lacunas, angústias e insatisfações daqueles que irão partir em busca de mais emoções, inspirações e recomeços.

A narrativa do personagem, em conjunto com as imagens de um lugar inóspito, em um ambiente natural a ser descoberto, neste e nos outros vídeos promocionais desta campanha, parecem tentar satisfazer o desejo do consumidor

de se reapropriar dos seus próprios prazeres, de viver a experiência de um modo mais pessoal, não conduzido, não orquestrado pelo mercado (...) Se, por vezes, prefere a simulação dirigida ao acaso do real, empenha-se mais ainda em redescobrir a "autencidade" da natureza, gerir seu lazer de forma individualizada. (Lipovetsky, 2007, p. 55)

Podemos inferir também, através do discurso do personagem e das imagens espetaculares do mar, que há uma alusão, ainda que não direta, às grandes navegações e descobertas ultramarinas portuguesas - contudo, dessa vez, quem vai explorar e descobrir novas experiências é o viajante que for a Portugal.

No entanto, o "consumo da experiência" contido no discurso escolhido pelo Turismo de Portugal para atrair o olhar e, mais do que isso, a visita do turista ao país, não preenche às categorias da definição proposta por Pereira, Siciliano \& Rocha $(2015$, p. 6), visto que não propõe o a existência de "um espaço físico ou virtual (...) intencionalmente preparado para que ele vivencie sensações, emoções e impressões dentro de um tempo delimitado e pontual" ou ainda "uma preparação ritualizada anterior, (...) suspensão da descrença face aos aspectos lúdicos, mágicos ou imaginados que serão, naquele espaço, apresentados como 'simulacro'”, dentre outros aspectos determinados pelos referidos autores. Entretanto, é inegável à alusão a vivência de experiências em um cenário natural idealizado (com uma praia na qual se pode nadar tranquilamente em pleno inverno europeu, por exemplo) a ser descoberto por um turista solitário. A narrativa do personagem central alude diretamente à realização da viagem enquanto experiência necessária para se sentir "vivo", de literalmente fugir de uma rotina estressante ou pouco interessante para descobrir sensações novas como o "sol a queimar-lhe as costas" ou o "vento gelado do topo da montanha".

Além disso, a partir do momento que o consumidor-turista, seduzido pelas imagens e discursos disponibilizados através do ecrã, deseja obter mais informações de como pode "comprar" estas experiências oferecidas, pode encontrar, na descrição do vídeo no YouTube alguns links. Entre os quais, está o site da Visit Portugal", no qual o usuário terá acesso a mais informações sobre as regiões, destinos e atrativos turísticos de Portugal.

Foi criado também um hotsite desenvolvido especificamente para a campanha ${ }^{12}$, com versões em seis idiomas diferentes (inglês, português, espanhol, francês, italiano e alemão). Neste site, o turista interessado no destino Portugal, terá acesso a um "guia emocional de viagem", com o subtítulo "Sinta e descubra um itinerário baseado nas

\footnotetext{
"Disponível em www.visitportugal.com

${ }^{12}$ Disponível em www.cantskipportugal.com/pt
} 
emoções. A vida é melhor quando não a deixamos passar ao lado". A partir da emoção ou estado de espírito que melhor lhe define ou inspire, o site irá direcioná-lo para as experiências e lugares de Portugal mais adequados ao seu anseio.

Assim, no menu de emoções, o futuro turista poderá escolher como se sentir: tranquilo, descontraído, glamoroso, alegre, extravagante, brincalhão, deslumbrado, curioso, inspirado, entusiasmado, vivo, saudável, romântico, animado, enérgico, aventureiro, criativo ou deliciado. Portanto, são oferecidas, como em uma prateleira virtual, emoções e experiências, a serem vividas nos diferentes sítios apresentados.

Diante do guia emocional de viagens, realizamos um breve exercício clicando em algumas das opções para observar o que é oferecido. Por exemplo, ao clicar em "extravagante", o site abre uma nova página, com cores vibrantes (vermelho e roxo), a palavra extravagante em destaque e, abaixo dela, o texto: "Liberte o seu espírito e desfrute da vida em Portugal - A comida e o vinho, os spas, as compras. Não sairá desapontado. Venha descobrir porquê!". Na mesma página, há três fotografias, cada uma delas identificada com seu próprio hashtag. Uma com a imagem de um homem olhando para um vale, enquanto segura uma taça de vinho e a legenda \#Wine. A outra imagem é a de uma mulher em posição de lótus, aparentemente meditando, ao lado de um rio ou lago e a legenda \#Wellness. Na terceira foto há uma imagem de uma comida com mariscos disposta em uma cataplana, utensílio típico utilizado na culinária portuguesa e a legenda \#Gastronomy. A partir de seu interesse, o usuário do site clica na foto para ter acesso a mais informações. Clicando, por exemplo, na foto identificada como \#Wellness, somos redirecionados para uma página do site da Visit Portugal'3 com o título "Dias de bem-estar num spa" e informações sobre programas de spa, resorts e hotéis, distribuídos pelo Norte, Centro e Algarve.

Mas, se quisermos, simplesmente nos sentirmos "vivos", clicamos, dentre as 18 opções do guia emocional de viagem disponíveis, na opção "vivo". Em uma página em tons de azul, verde e amarelo, nos é prometido "deliciosas refeições, paisagens inesquecíveis, atividades excitantes. Em Portugal, sentir-se vivo é obrigação". As hashtags \#Su$n$ AndSea (com a foto de uma pessoa caminhando em uma praia deserta), \#CityBreak (e a imagem de um homem, sozinho, na Ribeira do Porto) e \#FamilyHolidays (com a imagem de jovens/crianças em uma praia).

O guia emocional de viagem mostra-se, portanto, enquanto um guia de viagens diferente em relação aos tradicionais livros do gênero - que normalmente apresentam textos e imagens a respeito dos principais atrativos turísticos locais, incluindo dicas de passeios, restaurantes, museus ou outros lugares "imperdíveis". O guia emocional está centrado nas emoções e experiências que o consumidor quer vivenciar e, a partir daí, mostra-lhe o que fazer e aonde ir. O que vai guiá-lo não é a definição do destino, mas sim as escolhas emocionais que o viajante escolher "comprar".

As emoções e o "estilo de vida" como opções de escolha apresentam um direcionamento para a pseudo ideia de individualidade. Esta tendência de individualidade e de personalização está exponencializando as experiências turísticas contemporâneas.

\footnotetext{
${ }^{13}$ Disponível em www.visitportugal.com
} 
Contudo, esta personalização, nada mais é que a aplicação da (re)significação de um produto massivo para uma vertente individual. Tal estratégia pode ser observada nesta e em outras campanhas turísticas contemporâneas, com o objetivo de despertar as emoções e os sentidos para o consumo imediato da vontade, que despertará o desejo do consumo. Este jogo de signos de consumo só é possível através do advento da tecnologia digital, que está transformando o lugar da cultura e consequentemente do turismo.

As emoções e os sentimentos sensoriais proporcionados pelos ecrãs poderão ser vividos in loco. O futuro consumidor-turista teve apenas uma breve "amostra", através de imagens e discursos envolventes, do que promete ser uma viagem transformadora. Caso decida partir, terá a oportunidade de explorar, por si mesmo, aquilo que deseja sentir. Entretanto, propomos as seguintes reflexões: é possível comprar uma emoção? A viagem pode ser a materialização das experiências as quais anseiam os indivíduos na fuga de seus cotidianos enfadonhos ou estressantes? Podemos levar conosco esse conjunto de experiências vivenciadas em uma viagem e, ao final, chegarmos melhores e mais motivados para enfrentar o dia a dia caótico? Essas questões parecem confirmar a complexidade do consumo turístico e da experiência enquanto objeto a ser consumido na contemporaneidade.

\section{CONSIDERAÇÕES FINAIS}

$\mathrm{Na}$ tentativa de perceber como as transformações no consumo do lazer e do turismo contemporâneos são representadas e retroalimentadas pelo discurso promocional turístico, buscamos neste trabalho orientar o nosso olhar para o filme publicitário Can't Skip Freedom a partir da articulação com algumas considerações teóricas oriundas da Sociologia do Turismo e da Cultura a respeito do "consumo da experiência" e da perspectiva dos Estudos Culturais. Integrado à campanha online do Turismo de Portugal intitulada Can't Skip Portugal, observamos que o referido vídeo articula uma estratégia de atração e sedução através do uso de belas imagens do país e de um personagem-narrador que convida os espectadores a sentir e descobrir novas experiências através da realização de uma viagem.

Visto que não são utilizados elementos simbólicos ou signos que remetam diretamente a Portugal, a exemplo, construções históricas como igrejas, torres ou castelos, ou outros elementos da cultura portuguesa normalmente associados a este país (como o fado, o vira, os azulejos, entre outros), o discurso promovido através deste vídeo promocional divulga o país enquanto destino capaz de oferecer experiências e possibilitar emoções e sensações ao visitante. Desta forma, o consumo da experiência, ainda que não remeta a um imaginário anterior alusivo a este país, nem tampouco ofereça um espaço criado especificamente para a experiência, está presente no universo de sentido construído na campanha, seja através dos filmes publicitários, seja através do hotsite e seu "menu de emoções", pois remete à ideia de que a realização de uma viagem está mais ligada às experiências e emoções do que à contemplação "passiva" de atrativos turísticos já difundidos a respeito deste destino turístico anteriormente. 
Para concluir, a partir destas considerações a respeito das representações contidas nesta campanha que objetiva promover o turismo internacional em Portugal, sugerimos estudos a respeito de seu contexto de produção, incluindo as políticas de marketing que a fundamentou, e também os processos de recepção, tanto por parte dos públicos de turistas, como também por parte dos moradores dos destinos turísticos comercializados. Ademais, parece ser relevante para compreender a complexidade do fazer turístico analisar também os impactos que têm determinados modos de representação dos lugares, das culturas e de seus habitantes, enquanto partes integrantes de objetos de consumo de experiência.

\section{REFERÊNCIAS}

Bauman, Z. (1998). O mal-estar da pós-modernidade. Rio de Janeiro: Zahar.

Bauman, Z. (2007). Vida para consumo: a transformação das pessoas em mercadorias. Rio de Janeiro: Zahar.

Conceição, C. P. (1998). Promoção turística e (re)construção social da realidade. Sociologia: Problemas e Práticas, 28, 67-89. Retirado de http://sociologiapp.iscte.pt/pdfs/12/125.pdf

Escosteguy, A. C. (2007). Circuitos de cultura/circuitos de comunicação: um protocolo analítico de integração da produção e da recepção. Comunicação Mídia e Consumo, 4(11), 115-135. DOI: $10.18568 / 1983-7070.411115-135$

Lisboa Filho, F. F. \& Moraes, A. L. C. (2014). Estudos Culturais aplicados a pesquisas em mídias audiovisuais: o circuito da cultura como instrumental analítico. Significação, 41(42), 67-86. DOI: 10.11606/issn.23167114.sig.2014.85103

Hall, S. (2003). Representation: cultural representations and signifying practices. Londres: Sage.

Krippendorf, J. (2009). Sociologia do turismo: para uma nova compreensão do lazer e das viagens. São Paulo: Aleph.

Lipovetsky, G. (2007). A felicidade paradoxal: ensaio sobre a sociedade do hiperconsumo. Lisboa: Edições 70.

Lipovetsky, G. \& Serroy, J. (2008). A cultura-mundo: resposta a uma sociedade desorientada. Lisboa: Edições 70.

Martins, M. de L. (2017). Crise no castelo da cultura: das estrelas para os ecrãs. V. N. Famalicão: Humus.

Pereira, C. da S., Siciliano, T. \& Rocha, E. (2015). Consumo de experiência" e "experiência de consumo": Uma discussão conceitual. Logos, 22(2), 6-17. DOI: 10.12957/LOGOS.2015.19523

Ribeiro, R. (2010). Pensar a identidade atonal da modernidade: breve fantasia a quatro mãos. Comunicação $e$ Sociedade, 18, 193-200. DOI: 10.17231/comsoc.18(2010).998

Santos, J. M. F. (2008). Turismo e transfigurações culturais. Revista Encontros Científicos, 3, 109-124.

Turismo de Portugal. (2017). Estratégia Turismo 2027, 1-66. Retirado de http://estrategia.turismodeportugal. pt/sites/default/files/Estrategia_Turismo_2027_TdP.pdf

Urry, J (2001). O olhar do turista: Lazer e viagens nas sociedades contemporâneas. São Paulo: Studio Nobel, Sesc. 


\section{NotA BIOGRÁFICA}

Patrícia de Souza Figueiredo Lima é doutoranda em Estudos Culturais pela Universidade do Minho, mestra em Cultura e Sociedade pela Universidade Federal da Bahia (UFBA). Bacharela em Comunicação com habilitação em Produção em Comunicação e Cultura pela UFBA e Bacharela em Turismo e Hotelaria pela Universidade do Estado da Bahia (UNEB). Desenvolve, desde a graduação, investigação voltada para a relação entre a cultura, turismo, identidades, consumo e publicidade.

Email: patriciasfigueiredolima@gmail.com

Endereço: Rua do Timbó, 623, apto 1504, Salvador, Bahia, Brasil. CEP: 41820-66o

* Submetido: 28-02-2018

* Aceite: 12-09-2018 